\title{
More than an information service: are counselling skills needed by genetics professionals in the genomic era?
}

\author{
Heather Skirton ${ }^{1}$ \\ Received: 17 January 2018 / Revised: 26 February 2018 / Accepted: 2 March 2018 / Published online: 22 May 2018 \\ (c) European Society of Human Genetics 2018
}

Whether genetic counsellors are primarily educators or counsellors has long been debated [1], with a suggestion that integration of these two aspects was required [1]. In the age of genomic medicine, there is emphasis on the complex information that should be provided to enable informed decision-making and to gain consent for testing [2]. This has, in my opinion, led to an increasing emphasis on the educational role of the genetic counsellor, to the detriment of the counselling aspects of the role.

Despite the current emphasis on information-giving, a recent detailed qualitative study has reported genetic counselling as a pastoral interaction, in which the work of the counsellor is to establish a trusting relationship and enable the client to have confidence in their own decisions [3]. The authors [3] describe genetic counselling as a process in which a successful outcome is exhibited by shared understanding of uncertainties. The need for counselling within the process is affirmed by work by Austin et al. [4], who utilise a range of evidence to underpin their assertion that genetic counselling is not effective without the psychotherapeutic component. Decision-making in genomic testing can be even more complex than in 'traditional' genetics, as uncertainties regarding the pathogenicity of variants and how the penetrance of variants studied in affected families will apply to the general population are added to those regarding natural progression and prognosis of disease. I would therefore argue that, far from being outdated in the genomic counselling era, the focus on the use of counselling skills is highly relevant, as counselling skills are essential to enable the counsellor to determine

Heather Skirton: Retired from University of Plymouth.

Heather Skirton

Heather.skirton@plymouth.ac.uk

1 University of Plymouth, Drake Circus Plymouth, Plymouth PL4 8AA, UK whether the client's decision is 'authentic' and based on a reasonable understanding of their situation [3].

There is, however, anecdotal evidence of the trend away from the counselling model: I have spoken with genetic counsellors who state that they have to give so much information that they haven't time for counselling, and with patients who are distressed by a lack of psychosocial support from genetic counsellors. However, there is other more concrete evidence. For example, genetic counsellors in the Netherlands have now adopted the physician's assistant training route, with a commensurate emphasis on the biomedical model of care. In addition, the European Board of Medical Genetics (EBMG) Genetic Nurse and Genetic Counsellor branch has had to advise Masters programme directors that there is inadequate emphasis on counselling skills in some Masters training programmes. These issues point towards a devaluation of counselling skills and training in the profession.

The European competences for genetic counsellors used by the EBMG state that genetic counsellors must be able to establish a therapeutic relationship, assess understanding and needs, use counselling skills to facilitate clients' adjustment and decision-making, and engage in counselling supervision. While provision of information is undoubtedly important in genetic healthcare, it is the integration of genetics knowledge into their own lives that helps patients to deal with their situations [5]. Furthermore, expression of emotions about their personal situation helps patients to process information cognitively [6]. In healthcare situations generally, patients are more likely to recall the content of the discussion when their emotional cues are responded to by the health professional [7]. Therefore, even with the argument that information giving is important, it is more effective when counselling is embedded into the clinical session [7]. There is also evidence that integration of psychological counselling into healthcare reduces adverse psychological sequelae in other comparable healthcare situations, for example in women who have experienced perinatal loss or trauma [8] and couples coping with 
infertility [9], indicating that counselling input can contribute to overall psychological health and adjustment of service-users. Despite this, in a study of genetic counselling sessions [10], counsellors spent more than half the session time giving biomedical information and only $4 \%$ of session time helping clients to apply it to their lives.

To ensure we are working in a patient-centred way, it is still important to focus on the patient, to discover what the client wishes to learn, rather than focusing primarily on what we determine it is important to tell them [11]. This requires competence in counselling techniques and core skills.

Due to the nature of working with patients who inevitably have psychological sequelae as a result of being affected or at risk, genetic counsellors are prone to burnout [12]. One strategy used by health professionals to avoid the psychological burden of the work is to avoid discussion of emotions with patients. As a trainer of many hundreds of counsellors, I am very aware that when the counsellor is unsure of how to react to emotions and create appropriate boundaries, the default position is often to provide more information. As information providers, we are secure, we can set an agenda that suits us, and maintain the more powerful position in the relationship. This does not necessarily enable adaptation and informed decision-making, which are core aims of genetic counselling. Another issue that relates to burnout is the lack of counselling supervision. While most centres in Europe offer rigorous clinical supervision for professionals, counselling supervision is poorly understood and utilised. Counselling supervision should be mandatory for those working with patients and enables the practitioner to debrief, analyse and learn from their encounters with patients at a psychological level, to facilitate the psychological safety of both patients and practitioners.

So how can we ensure that we as genetic (and genomic!) health professionals serve the best needs of clients and prevent adverse psychological effects in ourselves?

(1) Ensure advanced counselling skills are integral to training those genetic health professionals who have direct patient contact

(2) Ensure that when students are selected for genetic counsellor programmes that an assessment of their suitability as a counsellor is made, for example by making counselling training a pre-requisite for applicants.

(3) Ensure ongoing opportunities for professional development in counselling skills are supported by clinical managers

(4) Ensure counselling supervision is mandatory (for more information about how this can be done, see the document on the EBMG genetic counsellor website at https://www.eshg.org/408.0.html)

(5) Ensure counselling skills are rigorously assessed as part of any for registration/certification process for genetic counsellors.

I urge all those involved in providing genetic counselling to achieve and maintain competence in counselling skills. This is essential to enable patients to utilise the information we provide, adapt to their situations and make the decisions that are ultimately most suited to them.

\section{Compliance with ethical standards}

Conflict of interest The authors declare that they have no conflict of interest.

\section{References}

1. Kessler S. Psychological aspects of genetic counseling. IX. Teaching and counseling. J Genet Couns. 1997;6:287-95.

2. Niemiec E, Vears DF, Borry P, Howard HC. Readability of informed consent forms for whole-exome and whole-genome sequencing. J Community Genet. 2017;9:143-51.

3. Arribas-Ayllon MS, Srikant. Counselling uncertainty: genetics professionals' accounts of (non) directiveness and trust/distrust. Health, Risk Soc. 2014;16:171-84.

4. Austin J, Semaka A, Hadjipavlou G. Conceptualizing genetic counseling as psychotherapy in the era of genomic medicine. J Genet Couns. 2014;23:903-9.

5. Brédart A, Kop JL, De Pauw A, Caron O, Fajac A, Noguès C, et al. Effect on perceived control and psychological distress of genetic knowledge in women with breast cancer receiving a BRCA1/2 test result. Breast. 2017;31:121-7.

6. Ellington L, Kelly KM, Reblin M, Latimer S, Roter D. Communication in genetic counseling: cognitive and emotional processing. Health Commun. 2011;26:667-75.

7. McLeod J, McLeod J. Research on embedded counselling: an emerging topic of potential importance for the future of counselling psychology. Couns Psychol Q. 2015;28:922.

8. Rogers J, Spink M, Magrill A, Burgess K, Agius M. Evaluation of a specialised counselling service for perinatal bereavement. Psychiatr Danub. 2015;27(Suppl 1):S482-5.

9. Chow K-M, Cheung M-C, Cheung IK. Psychosocial interventions for infertile couples: a critical review. J Clin Nurs. 2016;25:2101-13.

10. Roter D, Ellington L, Erby LH, Larson S, Dudley W. The Genetic Counseling Video Project (GCVP): models of practice. Am J Med Genet C Semin Med Genet. 2006;142C:209-20.

11. Riedijk S, Diderich KE, van der Steen SL, Govaerts LC, Joosten M, Knapen MF, et al. The psychological challenges of replacing conventional karyotyping with genomic SNP array analysis in prenatal testing. J Clin Med. 2014;3:713-23.

12. Bernhardt BA, Rushton CH, Carrese J, Pyeritz RE, Kolodner K, Geller G. Distress and burnout among genetic service providers. Genet Med. 2009;11:527-35. 